\title{
The Influence of Hardly Digestive Starch Granules on Sucrase and Isomaltase in Small Intestinal Mucosa of Rats
}

\author{
Shuzo FUJITA and Hidetsugu FUWA ${ }^{1}$ \\ Department of Food and Nutrition, Faculty of Science of Living, \\ Osaka City University, Sumiyoshi-ku, Osaka 558, Japan
}

(Received June 3, 1983)

\begin{abstract}
Summary The effects of potato-starch granules (PSG) on sucrase and isomaltase activities in the small intestinal mucosa of rats were examined by gel filtration on a Sephacryl S-300 column. Young and adult rats were administered the diet containing $50 \%$ of either PSG or pregelatinized potato starch (PPS) as a control for 7 days. Mucosal homogenates were prepared from the small intestine and separated into their component disaccharidases on the column. The sucrase activity, increased by feeding young rats on the PSG diet, was detected in the sucrase-isomaltase complex by changing the activity ratio of the two enzymes. In adult rats, however, the complex seemed to be mature and the increased sucrase moiety was newly combined with a free isomaltase moiety and comprised a portion of the complex. These changes were observed not only in soluble disaccharidases but also in membrane-bound ones. Furthermore, there was a remarkable change of sucrase activity in the distal portion of the small intestine rather than in the proximal.

Key Words starch granule digestion in rats, potato-starch granules (PSG), sucrase, isomaltase, sucrase-isomaltase complex, Sephacryl gelfiltration
\end{abstract}

The susceptibility of starch granules to digestion by amylase depends on the source of the starch and the enzyme. Starch granules of roots and tubers are generally more resistant to the action of amylase than those of cereals (1-3). Potatostarch granules (PSG) are the most resistant to amylase among various starch granules. We investigated the influence of hardly digestive starch such as PSG on digestive tracts and enzymes of rats, and showed that $\alpha$-amylase [EC 3.2.1.1.] activity in pancreas was significantly decreased by feeding rats on a PSG diet and that intestinal sucrase [EC 3.2.1.48] activity was significantly increased, but that intestinal maltase [EC 3.2.1.20] and isomaltase [EC 3.2.1.10] activities scarcely changed(4-6). These changes were also observed when feeding rats on a diet

\footnotetext{
${ }^{1}$ 藤田修三，不破英次
} 
containing dietary fiber of high water-holding capacity, for example Konbu, a kind of sea vegetable (7).

Among intestinal disaccharidases of mammals, isomaltase exists both in a free form and as a complex with sucrase $(8-10)$. However, little is known about whether the sucrase activity, increased by feeding rats on a PSG diet, actually operates via the sucrase-isomaltase complex and plays a role on the terminal digestion and absorption of the starch. This paper describes the fractionation of small intestinal disaccharidases by gel filtration on a Sephacryl S-300 column, to obtain detailed information on sucrase and isomaltase activities in the intestinal mucosa of rats.

\section{EXPERIMENTAL}

1. Animals and diets. Experimental diets were administered to male SpragueDawley rats, 4 and 8 weeks of age, for 7 days. Rats were housed in individual stainless-steel wire cages in a temperature-regulated $\left(22 \pm 2^{\circ} \mathrm{C}\right)$ and light-controlled (light from 08:00 to 20:00) room. One hundred grams of experimental diet (PSG diet) contained $25 \mathrm{~g}$ of casein, $50 \mathrm{~g}$ of $\mathrm{PSG}$ and $9 \mathrm{~g}$ of pre-gelatinized potato starch (PPS) to make a diet dumpling with water, $5 \mathrm{~g}$ of corn oil, $5 \mathrm{~g}$ of cellulose, $5 \mathrm{~g}$ of salt mixture, $0.85 \mathrm{~g}$ of water-soluble vitamins, $10 \mathrm{mg}$ of all rac- $\alpha$-tocopheryl acetate, $600 \mathrm{IU}$ of retinyl palmitate and $60 \mathrm{IU}$ of ergocalciferol(4). The control PPS diet contained $50 \mathrm{~g}$ of PPS instead of the PSG in the PSG diet. Animals were given water and the diet in the form of dumplings ad libitum. After experimental period, rats were anesthetized in an ether chamber and killed. The small intestine was removed and its mucosa was collected by scraping

2. Preparation of soluble and membrane-bound disaccharidases. Disaccharidases were prepared by the method of Yamada et al.(11). The intestinal mucosa was homogenized with 4 volumes of $10 \mathrm{~mm}$ sodium phosphate buffer, $\mathrm{pH}$ 7.2. To separate soluble enzymes from insoluble membrane-bound ones, the homogenate was centrifuged at $105,000 \times g$ for $1 \mathrm{~h}$. The supernatant was used since it contained soluble disaccharidases.

A preparation of the brush-border membrane was obtained by the method of Kessler et al. (12). The $105,000 \times g$ precipitate was suspended in 30 volumes of ice-

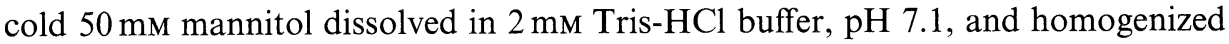
in a glass homogenizer with a Teflon pestle for $2 \mathrm{~min}$. Solid calcium chloride was added to the homogenate to give a final concentration of $10 \mathrm{~mm}$. After standing in an ice bath for $20 \mathrm{~min}$, the suspension was centrifuged at $3,000 \times g$ for $15 \mathrm{~min}$; the supernatant was centrifuged at $27,000 \times g$ for $30 \mathrm{~min}$. The pellets were then

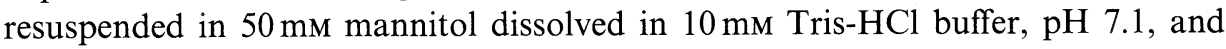
centrifuged at $27,000 \times g$ for $30 \mathrm{~min}$. The resultant pellets were resuspended in $2 \mathrm{ml}$ of $10 \mathrm{~mm}$ sodium phosphate buffer, $\mathrm{pH} 7.2$ (brush-border membrane suspension) and the suspension was incubated with $1.6 \mathrm{mg}$ papain and $4.0 \mathrm{mg}$ cysteine- $\mathrm{HCl}$ for $90 \mathrm{~min}$ at $37^{\circ} \mathrm{C}$. After papain treatment, the incubation mixture was centrifuged at $105,000 \times g$ for $1 \mathrm{~h}$. The supernatant was used for its membrane-bound disaccha- 
ridase content.

3. Sephacryl S-300 gel filtration. Either soluble or membrane-bound disaccharidase $(1.0 \mathrm{ml})$ was applied to a Sephacryl S-300 column $(1.5 \times 78 \mathrm{~cm})$ equilibrated with $10 \mathrm{~mm}$ sodium phosphate buffer, $\mathrm{pH} 7.2$, in a cold room. The same buffer was used for elution with a fraction volume of $2.5 \mathrm{ml}$ and flow rate of $14 \mathrm{ml}$ per $h$.

4. Assay procedures. Disaccharidase activities were determined by the method of Dahlqvist (13). Substrate concentration was $25 \mathrm{~mm}$ respectively of isomaltose, lactose, maltose and sucrose in $50 \mathrm{~mm}$ sodium acetate buffer, $\mathrm{pH} \mathrm{6.0.} \mathrm{One} \mathrm{unit} \mathrm{of}$ enzyme activity was defined as the amount of enzyme hydrolyzing $1 \mu \mathrm{mol}$ substrate in $1 \mathrm{~h}$ at $\mathrm{pH} 6.0$ and $37^{\circ} \mathrm{C}$. "Glucoamylase" activity was measured by the method of Schlegel-Haueter et al.(14). One unit of enzyme activity was defined as the amount of enzyme releasing $1 \mu \mathrm{g}$ of glucose from substrate in $1 \mathrm{~h}$.

\section{RESULTS}

\section{Mucosal disaccharidases on a Sephacryl S-300 column}

Sephacryl is a covalently cross-linked allyl dextran with $N, N^{\prime}$-methylene bisacrylamide and has rigid and highly stable matrices. Therefore, the gel may have the advantage of rapid separation of maltase, isomaltase and sucrase because of the higher affinity of the isomaltase to $\alpha$-1,6-glucosidic linkages in dextran such as Sephadex than that of the other enzymes.

As shown in Fig. 1, gel filtration of the intestinal preparations on the Sephacryl S-300 column revealed a major peak containing a sucrase-isomaltase complex accounting for about $90 \%$ of the total activity of sucrase and about $55 \%$ of the total

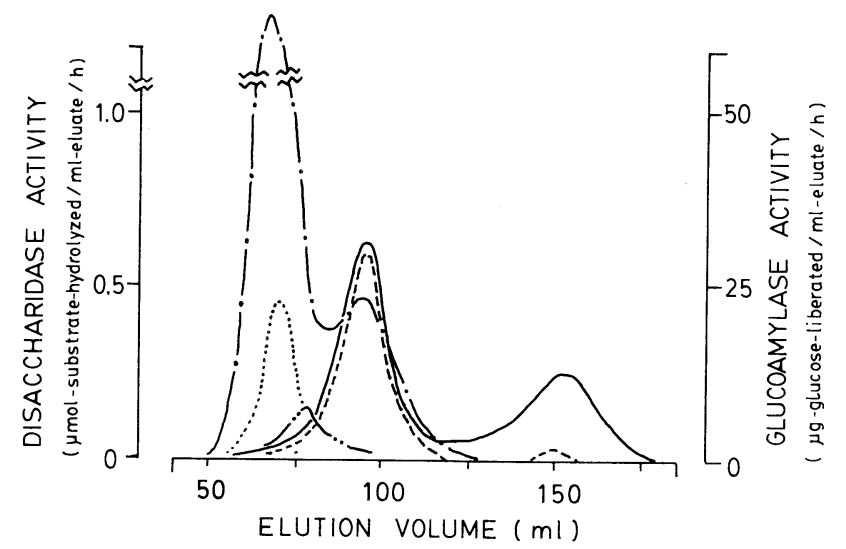

Fig. 1. Elution patterns of chromatography on a column of Sephacryl S-300 of several disaccharidases and "glucoamylase" of the small-intestinal mucosa in adult rats. - - isomaltase; ---, sucrase; -.--, maltase; -..-, lactase; -.----, "glucoamylase" activities. 


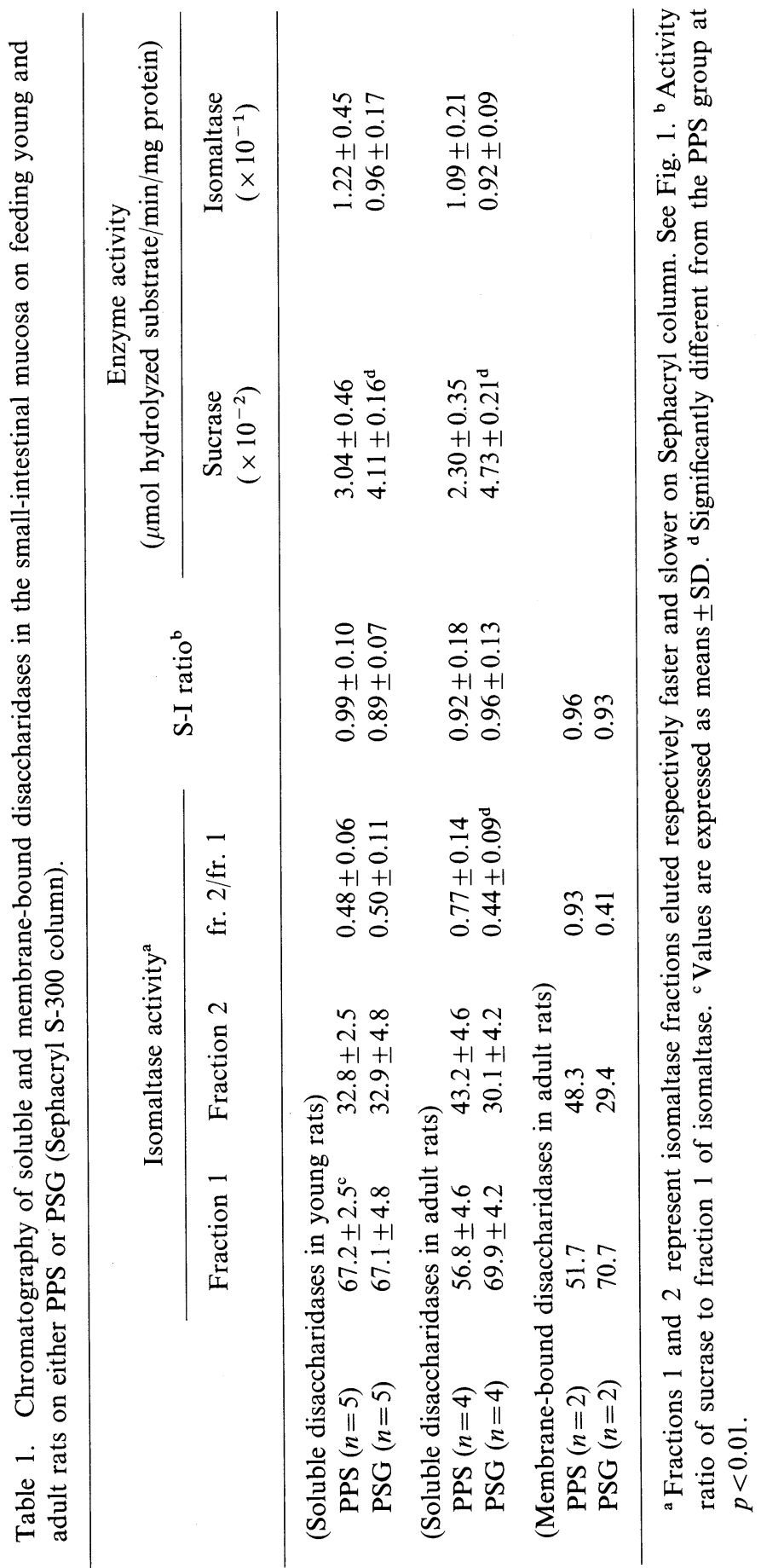




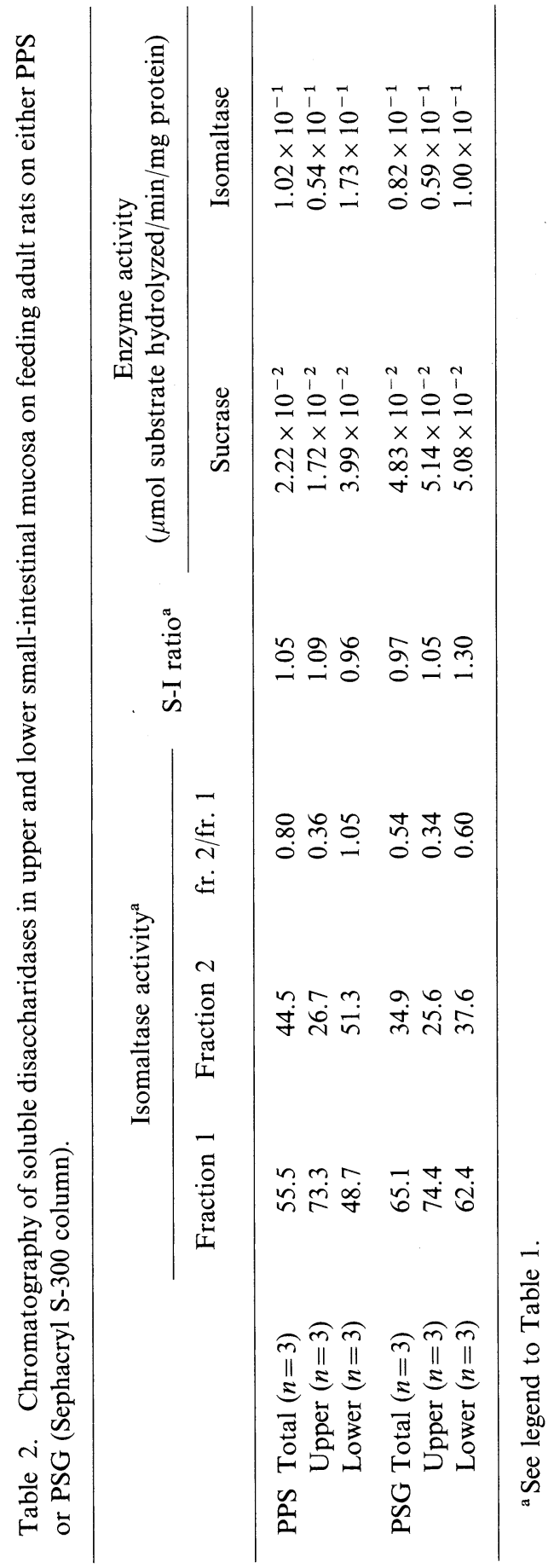

Vol. 30, No. 2, 1984 
activity of isomaltase in adults rats. Other peaks of sucrase and isomaltase were also detected. Two peaks having maltase activity were detected from chromatography as well as both chromatography on a Sephadex G-200 column (15) and acrylamidegel electrophoresis (10). The heavier maltase was associated with "glucoamylase" activity. Lactase was eluted in between the two maltases.

Elution profiles of sucrase and isomaltase of young rats, on the Sephacryl S-300 column

Chromatographic behavior of the soluble disaccharidases on the Sephacryl column was followed in order to determine whether the sucrase activity, increased by feeding rats on the PSG diet, exists as a complex with isomaltase. The elution profile of isomaltase on feeding rats on the PSG diet was similar to that of the control. The sucrase activity, increased by the substitution of PSG for PPS in the PPS diet, was then detected in the sucrase-isomaltase complex. The activity ratio of isomaltase to sucrase in the complex fraction decreased from 0.99 to 0.89 , while the ratio of total activity of isomaltase to that of sucrase was decreased from 1.45 to 1.05 as reported previously (6) (Table 1).

Elution profiles of sucrase and isomaltase of adult rats, on the Sephacryl S-300 column

In the case of the soluble disaccharidases of adult rats, the total activity ratio of isomaltase to sucrase decreased from 1.54 to 1.15 by the substitution of PSG for PPS in the PPS diet as well as in the case of young rats. However, the activity ratio of "slow" isomaltase (fraction 2) to "fast" isomaltase (fraction 1) decreased from 0.77 to 0.44 by feeding the rats on the PSG diet (Table 1). The sucrase-isomaltase ratio of the complex fraction was almost the same for the two groups. This means that feeding the rats on the PSG diet promotes the formation of the sucraseisomaltase complex in the small-intestinal mucosa of rats. The elution profiles of the membrane-bound enzymes were also similar to those of the respective soluble enzymes.

To obtain information on isomaltase and sucrase activities in each part of the small intestine, the tissue of adult rats was divided into upper and lower portions. The mucosal homogenates of each portion were then applied to the column. In the upper portion, probably corresponding to duodenum and jejunum, the activity ratio of fraction 2 (a free form) to fraction 1 ( a complex with sucrase) of isomaltase was similar in both the PSG and the control groups. However, in the lower portion, probably the ileum, the ratio was different between the PSG (0.60) and the control (1.05) (Table 2). The results suggested that the change of sucrase activity by feeding animals on the PSG diet occurred in the ileum rather than in the jejunum.

\section{DISCUSSION}

Sephacryl S-300 gel filtration is a useful device for taking an overall view of the 
elution profiles of several disaccharidases, especially isomaltase, offering a considerable reduction in time compared with Sephadex G-200 gel filtration. Moreover, isomaltase activity was eluted in order of molecular weight by the Sephacryl gel filtration because of the lesser content of dextran in the gel and the lower affinity to isomaltase than with Sephadex.

We reported in our previous paper (6) that the intestinal sucrase activity was increased by feeding young rats on the PSG diet. Our present study shows that the increased sucrase activity was detected in the sucrase-isomaltase complex and that some differences in the complex were observed between young and adult rats. Namely, from the elution profile, activity ratio of sucrase to isomaltase was decreased by feeding young rats on the PSG diet though the ratio did not change by feeding adult rats on the experimental diet.

Isomltase activity was separated into two fractions, fraction 1 (a complex with sucrase) and fraction 2 (a free form), as shown in Fig. 1 and the activity ratios of fraction 1 to fraction 2 of young and adult rats fed on the PPS diet were 0.48 and 0.77 , respectively (Table 2). Namely, isomaltase of adult rats consists of a relatively greater amount of the free form than is the case with young rats. The ratio scarcely changed by feeding young rats on the PSG diet. However, it was decreased from 0.77 to 0.44 by feeding adult rats on the diet. The results suggest that the sucrase activity, increased by feeding young rats on the PSG diet, may be combined with that of the pre-existing sucrase-isomaltase complex without changing the free isomaltase activity or may result from the activation of the inactive sucrase moiety contained in the complex. While the sucrase activity, increased by feeding adult rats on the experimental diet, was combined with the free isomaltase activity and resulted in a newly formed sucrase-isomaltase complex.

We cannot answer at present the question as to whether the increased sucrase activity is involved in the terminal digestion and absorption of potato-starch granules or not. However, a preliminary experiment on the action of disaccharidases fractionated by Sephacryl gel filtration on an $\alpha$-limit dextrin by pancreatic $\alpha$-amylase showed that the sucrase-isomaltase complex and the maltase fraction having "glucoamylase" activity degraded the $\alpha$-limit dextrin to a considerable extent. This suggested that an increase in the $\alpha$-limit dextrinase activity, which resulted from the increased sucrase activity in ileum by the substitution of PSG for PPS in the PPS diet, may play a role in the degradation of products of intestinal $\alpha$ amylolysis and may be a biochemically reasonable response for digestion and absorption of products derived by $\alpha$-amylolysis of indigestible starch granules.

\section{REFERENCES}

1) Fuwa, H. (1977): Digestion of various starch granules by amylase. Denpun Kagaku (J. Jpn. Soc. Starch Sci.), 24, 128-140.

2) Sugimoto, Y., Onishi, K., Takaya, T., and Fuwa, H. (1979): Comparative susceptibility to pancreatin of starch granules from different plant species. Denpun Kagaku (J. Jpn. 
Soc. Starch Sci.), 26, 182-190.

3) Fuwa, H., Takaya, T., and Sugimoto, Y. (1980): Degradation of various starch granules by amylases, in Mechanisms of Saccharide Polymerization and Depolymerization, ed. by Marshall, J. J., Academic Press, Inc., New York, pp. 73-100.

4) Fujita, S., Takaya, T., and Fuwa, H. (1981): Effects of potato starch granules on digestive enzymes of rats. Eiyo To Shokuryo (J. Jpn. Soc. Food Nutr.), 34, 287-294.

5) Fujita, S., Glover, D. V., Sugimoto, Y., and Fuwa, H. (1982): Effects of partially digestible starch-granules on digestive enzymes of rats. Nutr. Rep. Int., 26, 175-181.

6) Fujita, S., Sugimoto, Y., and Fuwa, H. (1983): Some characteristics of air-classified potato starch granules and their effects on digestive function of rats. Nippon Eiyo Shokuryō Gakkaishi (J. Jpn. Soc. Nutr. Food Sci.), 36, 453-459.

7) Fujita, S., and Fuwa, H. (1983): The influence of Konbu and Shiitake on digestive enzymes of rats. Nippon Eiyō Shokuryō Gakkaishi (J. Jpn. Soc. Nutr. Food Sci.), 36, 265-271.

8) Dahlqvist, A., and Telenius, U. (1969): Column chromatography of human small intestinal maltase, isomaltase and invertase activities. Biochem. J., 111, 139-146.

9) Kolinska, J., and Kraml, J. (1972): Separation of sucrase-isomaltase and of glucoamylase of rat intestine. Biochim. Biophys. Acta, 284, 235-247.

10) Maestracci, D., Preiser, H., Hedges, T., Schmitz, J., and Crane, R. K. (1975): Enzymes of the human intestinal brush border membrane. Identification after gel electrophoretic separation. Biochim. Biophys. Acta, 382, 147-156.

11) Yamada, K., Moriuchi, S., and Hosoya, N. (1978): Developmental changes in the sucrase-isomaltase complex in rat intestinal mucosa. J. Nutr. Sci. Vitaminol., 24, 177184.

12) Kessler, M., Acuto, O., Storelli, C., Murer, H., Müller, M., and Semenza, G. (1978): A modified procedure for the rapid preparation of efficiently transporting vesicles of Dglucose and choline transport system. Biochim. Biophys. Acta, 506, 136-154.

13) Dahlqvist, A. (1964): Method for assay of intestinal disaccharidases. Anal. Biochem., 7, $18-25$.

14) Schlegel-Haueter, S., Hore, P., Kerry, K. P., and Semenza, G. (1972): The preparation of lactase and glucoamylase of rat small intestine. Biochim. Biophys. Acta, 258, 506519.

15) Sasaki, M., Yamada, K., Moriuchi, S., and Hosoya, N. (1979): Purification and characterization of rat intestinal sucrase-isomaltase complex. Eiyo To Shokuryo (J. Jpn. Soc. Food Nutr.), 32, 201-208. 